\title{
Genomic analysis of Staphylococcus aureus from the West African Dwarf (WAD) goat in Nigeria
}

Adebayo Osagie Shittu ${ }^{1,2^{*}}$ DD, Fadekemi Funmilayo Taiwo ${ }^{1}$, Neele Judith Froböse ${ }^{2}$, Bianca Schwartbeck ${ }^{2}$, Silke Niemann ${ }^{2}$, Alexander Mellmann ${ }^{2,3}$ and Frieder Schaumburg ${ }^{2}$

\begin{abstract}
Background: Staphylococcus aureus can colonize various host species, and human-animal interaction is a significant factor for cross-species transmission. However, data on S. aureus colonization in animals, particularly on ruminants in close contact with humans, is limited. The West African Dwarf (WAD) goat is among the earliest domesticated ruminant associated with rural dwellers and small-holder farmers in sub-Saharan Africa. This study aimed to investigate the population structure, antibiotic resistance, and virulence gene determinants of $S$. aureus from the WAD goat in Nigeria.

Methods: Nasal samples were obtained from the WAD goat in five markets in Osun State, South-West Nigeria. S. aureus was characterized by antibiotic susceptibility testing, detection of virulence determinants, spa typing, and multilocus sequence typing (MLST). Representative isolates were selected for whole-genome sequencing, biofilm, and cytotoxicity assay.

Results: Of the 726 nasal samples obtained from the WAD goat, 90 S. aureus (12.4\%) were recovered. Overall, 86 isolates were methicillin-susceptible, and four were mecA-positive (i.e., methicillin-resistant S. aureus [MRSA]). A diverse S. aureus clonal population was observed (20 sequence types [STs] and 37 spa types), while 35\% (13/37) and 40\% (8/20) were new spa types and STs, respectively. Eleven MLST clonal complexes (CC) were identified (CC1, CC5, CC8, CC15, CC30, CC45, CC97, CC121, CC133, CC152, CC522). The MRSA isolates were designated as t127-ST852-CC1SCCmec type VII, t4690-ST152-CC152-SCCmec type Vc, and t8821-ST152-CC152-SCCmec type Vc. Phylogenetic analysis revealed that $60 \%$ (54/90) of all isolates were associated with ruminant lineages (i.e., CC133, CC522). Panton-Valentine Leukocidin (PVL)-positive S. aureus was identified in CC1, CC30, CC121, and CC152. For the CC522 isolates, we illustrate their pathogenic potential by the detection of the toxic shock syndrome gene and hemolysins, as well as their strong cytotoxicity and ability to form biofilms.
\end{abstract}

Conclusions: This is the first detailed investigation on the genomic content of $S$. aureus from the WAD goat in Nigeria. The S. aureus population of the WAD goat consists mainly of ruminant-associated lineages (e.g., CC133, CC522), interspersed with human-associated clones, including PVL-positive MRSA CC1 and CC152.

Keywords: Staphylococcus aureus, Ruminants, Goats, Whole-genome sequencing, Nigeria

*Correspondence: bayo_shittu@yahoo.com

${ }^{2}$ Institute of Medical Microbiology, University Hospital Münster, Domagkstraße 10, 48149 Münster, Germany

Full list of author information is available at the end of the article

\section{Introduction}

Staphylococcus aureus is a commensal inhabiting the skin and mucous membranes and a pathogen associated with a range of human and livestock diseases [1]. It colonizes various hosts mainly through genomic diversification and original author(s) and the source, provide a link to the Creative Commons licence, and indicate if changes were made. The images or other third party material in this article are included in the article's Creative Commons licence, unless indicated otherwise in a credit line to the material. If material is not included in the article's Creative Commons licence and your intended use is not permitted by statutory regulation or exceeds the permitted use, you will need to obtain permission directly from the copyright holder. To view a copy of this licence, visit http://creativecommons.org/licenses/by/4.0/. The Creative Commons Public Domain Dedication waiver (http://creativeco mmons.org/publicdomain/zero/1.0/) applies to the data made available in this article, unless otherwise stated in a credit line to the data. 
acquisition or loss of mobile genetic elements (MGEs), encoding immune evasion factors, leukocidins, and superantigens $[2,3]$. The close contact between animals and humans and increased industrialization of livestock farming facilitate $S$. aureus host-switching and adaptation events [4]. S. aureus infections are of great concern in the dairy industry (comprising mainly cow, sheep, and goat) with economic implications [5]. Moreover, animals as a reservoir for $S$. aureus colonization portend serious consequences to human health [3].

From 2009 to 2013, an increase (18.3-42.3\%) in the prevalence of methicillin-resistant S. aureus (MRSA) was observed with regional variations in Nigeria [6]. Also, studies based on two molecular typing schemes, i.e., Staphylococcus protein A (spa) typing and multilocus sequence typing (MLST), have provided evidence on some dominant clones. They include t064-CC8, t037-CC239 (MRSA) [7], and t084-CC15, t355-CC152 in methicillin-susceptible $S$. aureus (MSSA) [8]. Furthermore, the Panton-Valentine Leukocidin (PVL), a bi-component pore-forming toxin, is widespread among MSSA in CC121 $[9,10]$ and CC152 $[8,10]$. Data on the molecular epidemiology of animal S. aureus in Nigeria is limited. Nevertheless, studies have observed a diverse $S$. aureus population, including human-associated lineages such as CC15 (PVL+) [11, 12], CC88 [12, 13], CC121 (PVL+), and CC152 (PVL+) [14] from food animals and their associated products.

The West African Dwarf (WAD) goat (Capra hircus) is a domesticated ruminant associated with humans and livestock farming in sub-Saharan Africa [15]. It is a major livestock resource, particularly among rural dwellers and small-holder farmers in West and Central Africa [16]. As of 2012, the goat population in Nigeria was 81 million, and it is estimated to reach 208 million by 2050 [17]. The close and long-standing interaction of the WAD goat with humans underscores the need to investigate possible $S$. aureus cross-species transmissions. The aim was to describe the clonal structure, antibiotic resistance, and virulence gene determinants of $S$. aureus in the WAD goat in Nigeria.

\section{Materials and methods}

\section{Nasal sample collection}

This study included WAD goats from the animal market located in five towns in Osun State, South-West Nigeria (Fig. 1a). The sampling period was from July 2018 to August 2019. A holding structure held the goats (Fig. 1b), and at each sampling event, all the animals in the custody of participating sellers were included. The subsequent visit to these markets was predicated on new animal stock information (provided by the sellers), thereby ruling out multiple sampling of individual goats. A nasal swab was taken using a sterile cotton swab stick (Sterilin, UK), moistened with sterile $0.85 \% \mathrm{NaCl}$ solution, placed back to the swab pouch, and promptly transported to the laboratory. This step was followed by enrichment in nutrient broth (MAST Diagnostic, UK) overnight at $37^{\circ} \mathrm{C}$. Thereafter, $10 \mu \mathrm{l}$ of the broth culture was streaked on Mannitol Salt Agar (MAST Diagnostic, UK) and incubated at $37{ }^{\circ} \mathrm{C}$ for $48 \mathrm{~h}$.
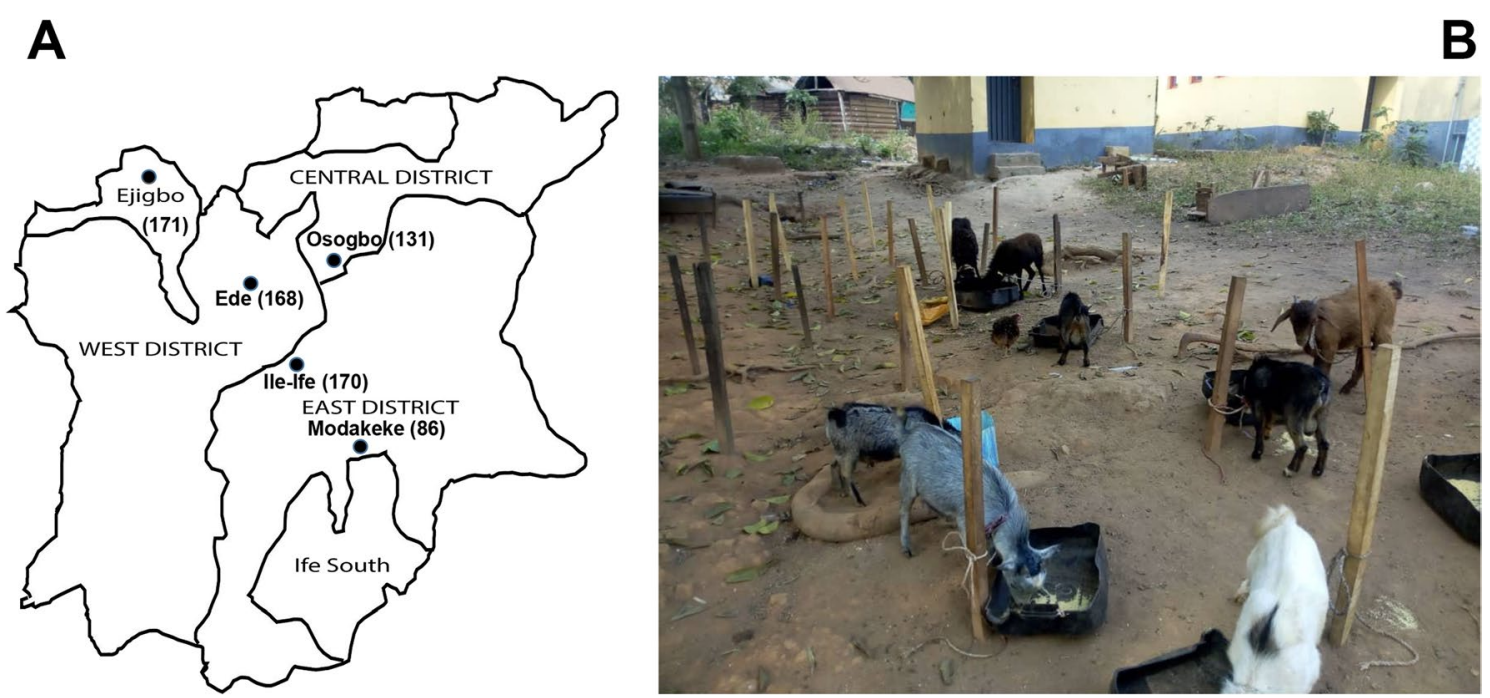

Fig. 1 a The sampling of the WAD goats in markets located in five locations in Osun State, Nigeria. a Map of Osun State indicating the locations [62]. The number of nasal samples (in parenthesis) is indicated for each location. $\mathbf{b}$ The WAD goats in one of the markets 


\section{Characterization of S. aureus isolates}

Preliminary identification as $S$. aureus was based on Gram staining and a positive catalase, coagulase, and DNase reaction. Isolates were confirmed as $S$. aureus by MALDI-TOF MS (Bruker Daltonics, Bremen, Germany), PCR detection of the $S$. aureus specific thermostable nuclease (nuc) [18], and nonribosomal peptide synthetase (NRPS) genes [19]. Methicillin-resistant $S$. aureus (MRSA) was confirmed by the detection of mecA [20]. Isolates were subjected to antimicrobial susceptibility testing (Vitek 2 automated system bioMérieux, Marcy l'Étoile, France) using EUCAST clinical breakpoints (Version 11.0), spa typing [21], and PCR detection of virulence (lukS/lukF-PV, chp, sak, scn) genes [22, 23].

\section{Whole-genome sequencing}

One $S$. aureus representing each spa type $(\mathrm{n}=37)$ was selected for whole-genome sequencing (WGS) on an Illumina MiSeq or NextSeq platform (Illumina Inc., San Diego, USA) with a $250-/ 150$ bp paired-end protocol aiming for $100 \times$ coverage [24]. Subsequently, reads were de novo-assembled using the SKESA assembler integrated into the SeqSphere ${ }^{+}$software (version 7.0, Ridom $\mathrm{GmbH}$, Münster, Germany). The antimicrobial resistance and virulence genes and multilocus sequence types (ST) were predicted in silico using SeqSphere ${ }^{+}$as recently described [25]. The staphylococcal cassette chromosome mec (SCCmec) types of the MRSA isolates were determined by the SCCmecFinder 1.2 [26] from the Centre for Genomic Epidemiology (https://cge.cbs.dtu.dk/servi ces/SCCmecFinder/; accessed on 22 April 2021). The raw reads of the representative isolates were deposited in the European Nucleotide Archive (https://www.ebi.ac.uk/ ena) under the project accession number PRJEB44433. The Neighbor-Joining (NJ) tree was constructed using 1861 genes of the $S$. aureus core genome multilocus sequence typing (cgMLST) scheme (Task templates: $S$. aureus cgMLST v1.3, pairwise ignore missing values).

\section{Screening for hemolytic activity and PCR detection of hemolysin ( $h l a$ and $h / b$ ) genes}

One $S$. aureus of each spa type in the CC522 lineage $(n=9)$ was screened for hemolytic activity on Columbia sheep blood agar (CBA, BD, Sparks, MD, USA). Colonies were examined for hemolysis after CBA plates were stored at $4{ }^{\circ} \mathrm{C}$ for $24 \mathrm{~h}$ with an earlier overnight incubation at $37^{\circ} \mathrm{C}[27,28]$. The presence of the hemolysin ( $h l a$ and $h l b)$ genes was also determined by PCR $[29,30]$. $S$. aureus identified with an intact $h l b$ (based on WGS) was also evaluated, and a positive and negative PCR result indicated a non-truncated or truncated $h l b$, respectively.

\section{Mucoidy and biofilm assay}

Isolates representing the CC522 lineage were assessed for mucoidy on CBA. Two characteristics determined the criteria for mucoidy: (a) colonies stick tightly to the CBA plate and (b) colonies with chewing gum-like texture, as assessed by an inoculating loop, after overnight incubation at $37{ }^{\circ} \mathrm{C}$ [27]. Mucoid isolates were identified and further screened on modified Congo Red Agar (CRA) composed of brain heart infusion broth (37 g/l, VWR Chemicals BDH, Leuven, Belgium), bacteriological agar (15 g/l, VWR Chemicals BDH, Leuven, Belgium), sucrose (36 g/l, Neofroxx GmbH, Germany) and Congo Red $(0.8 \mathrm{~g} / \mathrm{l}$, Waldeck GmbH \& Co KG, Münster, Germany) [31]. The colony characteristics were noted after incubation at $37^{\circ} \mathrm{C}$ for $72 \mathrm{~h}$. To determine the amount of biofilm produced by the mucoid CC522 isolates, a static 96-well microtiter plate (MTP) assay was performed as described previously [32]. The absorbance of adherent biofilm cells was measured with a microtiter plate reader (Bio-Rad, Hercules, CA, USA) at $655 \mathrm{~nm}$. Moreover, in parallel experiments, the nature of biofilms was analyzed. Biofilms were treated with sodium metaperiodate (NMP), which breaks down polysaccharide-mediated biofilms, and by proteinase $\mathrm{K}$ or DNase I, which disrupts protein- or DNA-dependent biofilms, respectively. Each mucoid S. aureus isolate was investigated in three biological replicates in eight wells per microtitre plate. Four isolates were used as controls: two biofilm-negative strains (S. carnosus TM300 and S. aureus $5 \mathrm{bpdel}^{-}$), a biofilm-positive strain (S. epidermidis RP62A (ATCC 35984) and the $S$. aureus CF-70518005-I (5bpdel ${ }^{+}$) that produces a biofilm, which consists of polysaccharide intercellular adhesin (PIA). PCR detection of the $i c a A$ and $i c a C$ genes was also performed, as previously described [32].

\section{Cytotoxicity assay}

The representative CC522 isolates $(n=9)$ were evaluated for cytotoxicity. The toxicity of $20 \%$ bacterial supernatant (overnight culture in tryptone soy broth [TSB]) on A549, a human alveolar epithelial cell line (ACC 107, DSMZ, $\mathrm{GmbH}$, Braunschweig, Germany), was determined after $24 \mathrm{~h}$ incubation using flow cytometry [33]. Cytotoxicity was indicated as the proportion of dead (i.e., \% of propidium iodide [PI]-positive) A549 cells. Cells treated with $20 \%$ TSB served as control.

\section{Statistical analysis}

The level of agreement between antibiotic susceptibility testing (AST) and detection of antibiotic resistance genes (WGS) was determined by Cohen's $\kappa$ test [34]. The $\kappa$ test was also utilized to determine the level of agreement between PCR and WGS in detecting Panton-Valentine 
leukocidin (PVL) and immune evasion cluster (IEC) genes. The $\kappa$ coefficient was interpreted as no agreement $(\kappa<0)$, slight agreement ( $\kappa: 0.00-0.20)$, fair agreement (к: $0.21-0.40$ ), moderate agreement ( $\kappa: 0.41-0.60)$, substantial agreement ( $\kappa: 0.61-0.80$ ), almost perfect agreement (к: 0.81-1.00) [34]. The analysis was performed using GraphPad Prism (https://www.graphpad.com/quick calcs/kappa1/). In the static biofilm and detachment assay, results were indicated as means and standard deviation on GraphPad Prism 5.0 (GraphPad Software, Inc., San Diego, CA). A two-way ANOVA with the Bonferroni posthoc test was utilized to compare the absorbance values of the different groups (buffer, NMP, proteinase $\mathrm{K}$, and DNase I) in the biofilm assay. In the cytotoxicity assay, the percentage of PI-positive mean values were analyzed using one-way ANOVA and compared with the negative control using Dunnett's multiple comparison test on GraphPad Prism. $P<0.05$ was considered significant.

\section{Results}

\section{Antibiotic susceptibility of S. aureus}

Of the 726 nasal samples, 90 were positive for $S$. aureus (12.4\%; one isolate per sample). All isolates were susceptible to glycopeptides, clindamycin, daptomycin, fosfomycin, fusidic acid, levofloxacin, linezolid, mupirocin, rifampicin, and tigecycline (Table 1). Moreover, 56\%
(50/90) were susceptible to all tested antibiotics (Additional file 1: Table S1). Four were identified as MRSA (mecA-positive). When comparing AST and WGS, a slight agreement was observed for fosfomycin and erythromycin ( $\kappa: 0.00)$. Substantial to almost perfect agreement was noted for gentamicin ( $\kappa: 0.65)$, tetracycline ( $\kappa$ : 0.72 ), penicillin ( $\kappa: 0.73$ ) and oxacillin ( $\kappa: 1.00)$, respectively (Additional file 2: Table S2).

\section{Genotyping of isolates}

The isolate collection consists of 37 spa types, including 13 new ones. MLST identified 20 STs with eight new STs (Table 2). Overall, the predominant spa-CC types comprised t3576-CC522 ( $\mathrm{n}=15), \mathrm{t} 10018-\mathrm{CC} 522$ $(\mathrm{n}=12), \mathrm{t} 18949-\mathrm{CC} 97(\mathrm{n}=7), \mathrm{t} 9268-\mathrm{CC} 522(\mathrm{n}=6)$ and t18947-CC133 $(\mathrm{n}=4)$. The MRSA isolates were classified as t127-ST852-CC1-SCCmec type VII $(\mathrm{n}=2)$, t4690-ST152-CC152-SCCmec type Vc $(\mathrm{n}=1)$, and $\mathrm{t} 8821$ ST152-CC152-SCCmec type Vc $(\mathrm{n}=1$, Table 2; Additional file 3: Fig. S3). Based on the construction of the NJ tree, the isolates were assigned into three main clusters (Fig. 2). Cluster A was a divergent group consisting of $\mathrm{CC} 1, \mathrm{CC} 5, \mathrm{CC} 8, \mathrm{CC} 15, \mathrm{CC} 97$, and ST6096. Cluster B is made up of closely related ruminant-associated lineages comprising CC133 and CC522, including CC121. CC30, CC45, CC152, and ST6082 were grouped with cluster C.

Table 1 Antibiotic susceptibility of S. aureus isolates from the WAD goat in Nigeria

\begin{tabular}{|c|c|c|c|c|c|c|}
\hline \multirow[b]{2}{*}{ Antimicrobial Agent } & \multicolumn{3}{|c|}{ MSSA $(n=86)$} & \multicolumn{3}{|c|}{ MRSA $(n=4)$} \\
\hline & $\mathbf{R}$ & 1 & $S$ & $\mathbf{R}$ & I & $\mathrm{S}$ \\
\hline Penicillin & 27 & - & 59 & 4 & - & 0 \\
\hline Oxacillin & 0 & - & 86 & 4 & - & 0 \\
\hline Gentamicin & 1 & - & 85 & 0 & - & 4 \\
\hline Levofloxacin & 0 & 0 & 86 & 0 & 0 & 4 \\
\hline Azithromycin & 1 & 0 & 85 & 0 & 0 & 4 \\
\hline Clarithromycin & 1 & 0 & 85 & 0 & 0 & 4 \\
\hline Erythromycin & 1 & 0 & 85 & 0 & 0 & 4 \\
\hline Clindamycin & 0 & 0 & 86 & 0 & 0 & 4 \\
\hline Linezolid & 0 & - & 86 & 0 & - & 4 \\
\hline Daptomycin & 0 & - & 86 & 0 & - & 4 \\
\hline Teicoplanin & 0 & 0 & 86 & 0 & 0 & 4 \\
\hline Vancomycin & 0 & 0 & 86 & 0 & 0 & 4 \\
\hline Tetracycline & 9 & 7 & 70 & 4 & 0 & 0 \\
\hline Tigecycline & 0 & - & 86 & 0 & - & 4 \\
\hline Fosfomycin & 0 & - & 86 & 0 & - & 4 \\
\hline Fusidic acid & 0 & - & 86 & 0 & - & 4 \\
\hline Mupirocin & 0 & - & 86 & 0 & - & 4 \\
\hline Rifampicin & 0 & 0 & 86 & 0 & 0 & 4 \\
\hline Cotrimoxazole & 6 & 2 & 78 & 3 & 1 & 0 \\
\hline
\end{tabular}

MSSA: Methicillin-susceptible Staphylococcus aureus; MRSA: Methicillin-resistant Staphylococcus aureus; S, Susceptible; I, susceptible, increased exposure; R, Resistant 
Table 2 Characterization and detection of selected antibiotic and virulence genes (WGS) in S. aureus isolates from the WAD goat in Nigeria

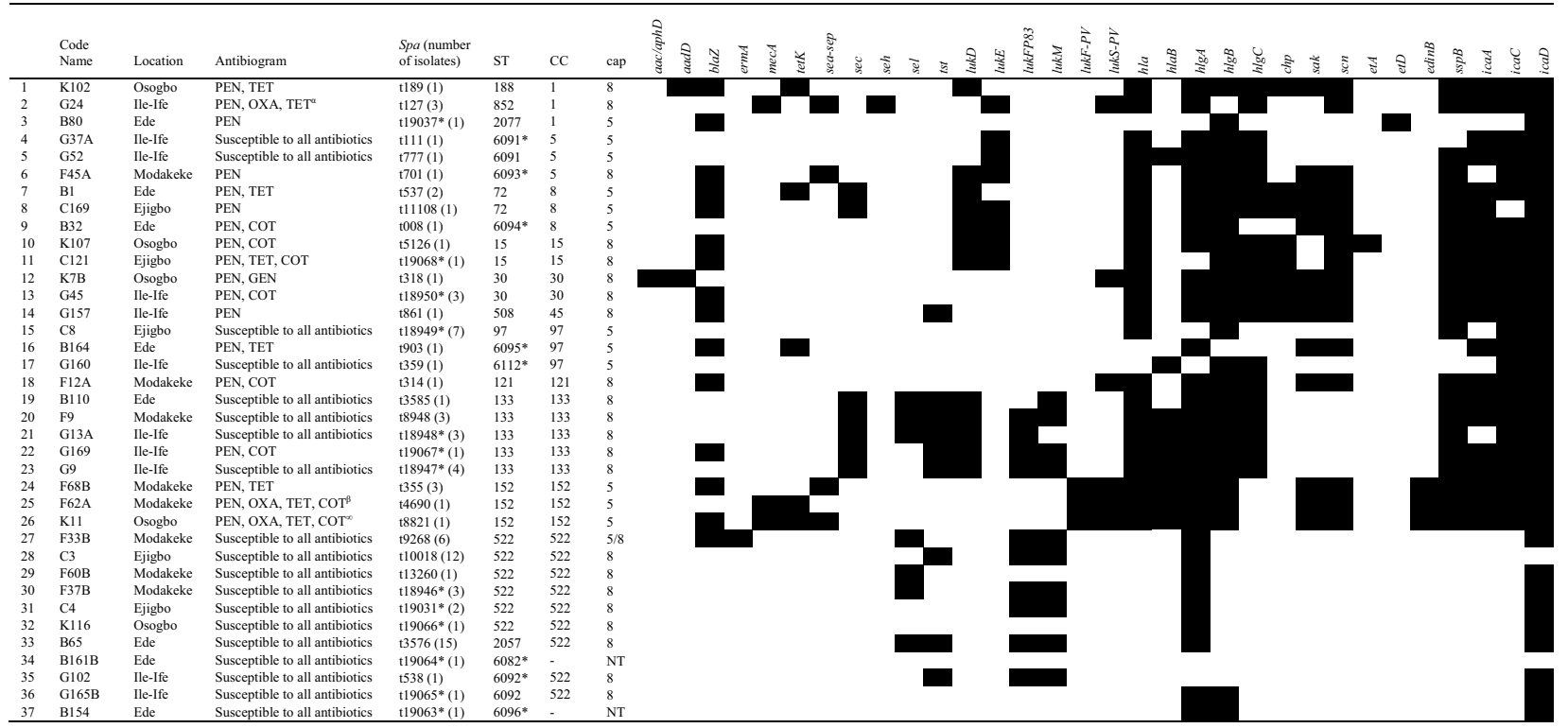

PEN, Penicillin; GEN, Gentamicin; OXA, Oxacillin; TET, Tetracycline; COT, Trimethoprim-sulphamethoxazole; spa, Staphylococcus protein A; ST, Sequence Type; CC, clonal complex; cap, capsule; Antibiotic resistance genes/product (aacA-aphD, bi-functional aminoglycoside phosphotransferase; aad $D$, aminoglycoside adenyltransferase; blaZ, $\beta$-lactamase; ermA, rRNA adenine N-6-methyl-transferase gene; mecA, alternate penicillin-binding 2a; tetK, tetracycline efflux protein variant $\mathrm{K}$ ). Enterotoxins and toxic shock syndrome genes (sea-sep, enterotoxin $A$ and $P$; sec, enterotoxin $C$; seh, enterotoxin $\mathrm{H}$; tst, toxic shock syndrome toxin). Leukocidin and hemolysin genes

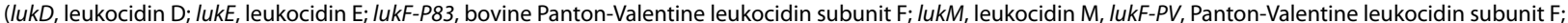
lukS-PV Panton-Valentine leukocidin subunit $S$; $h l a$, hemolysin alpha; hlaB, hemolysin $B ; h l g A$, hemolysin gamma component $A ; h l g B$, hemolysin gamma component $B$; $h l g C$, hemolysin gamma component C). Immune evasion cluster genes (chp, chemotaxis-inhibiting protein; sak, staphylokinase; scn; staphylococcal complement inhibitor). Exfoliative toxin and epidermal cell differentiation genes (etA, exfoliative toxin $A$; et $D$, exfoliative toxin $D$, edin $B$, epidermal cell differentiation inhibitor B). Proteases (sspB, staphopain B). Biofilm associated genes (icaA, intercellular adhesion gene $A ; i$; $c$ C , intercellular adhesion gene $C$; icaD, intercellular adhesion gene $D$ ) $\square$ negative positive; ${ }^{*}$ new spa types and sequence types; ${ }^{a}$ : t127-ST852-CC1-SCCmecVII; ${ }^{\beta}$ : t4690-ST152-CC152-SCCmecVc; ${ }^{\infty}$ : t8821-ST152-CC152-SCCmecVc

\section{PCR detection of PVL and IEC genes}

PVL-positive $S$. aureus was identified in CC1 $(\mathrm{n}=2)$, CC30 $(\mathrm{n}=4), \operatorname{CC} 121(\mathrm{n}=1)$ and $\mathrm{CC} 152(\mathrm{n}=5)$ including MRSA in $\mathrm{CC} 1(\mathrm{n}=2)$ and $\mathrm{CC} 152(\mathrm{n}=2)$. Furthermore, PCR detection of the IEC genes showed that isolates in CC30 and CC45 were chp/sak/sch-positive including CC1 $(n=2)$, CC8 $(n=2)$, and CC152 $(n=1$, Additional file 1: Table S1). CC15 isolates were uniquely $\mathrm{chp} / \mathrm{scn}$ positive, while those assigned with $\mathrm{CC} 1(\mathrm{n}=2), \mathrm{CC} 5$ $(\mathrm{n}=1), \operatorname{CC} 8(\mathrm{n}=1), \mathrm{CC} 97(\mathrm{n}=1), \mathrm{CC} 121(\mathrm{n}=1), \mathrm{CC} 152$ $(\mathrm{n}=3)$ were $s a k / s c n$ positive. The IEC genes were not detected in CC133, CC522, ST6082, and ST6096 including S. aureus in CC1 $(\mathrm{n}=1), \mathrm{CC} 5(\mathrm{n}=2), \mathrm{CC} 8(\mathrm{n}=1)$ and CC97 $(n=1)$. We observed a high level of agreement ( $\mathrm{k}$ : 0.9-1.00) between PCR and WGS in the detection of the above-mentioned IEC genes, while moderate agreement (к: 0.55) was noted for the detection of the PVL gene (Additional file 4: Table S4).

\section{Antibiotic resistance genes and $S$. aureus lineages}

WGS and MLST showed that blaZ conferring beta-lactam resistance was identified in all CCs. However, most of the isolates in CC133 and CC522 were blaZ-negative
(Table 2). Only one CC30 isolate with phenotypic resistance to gentamicin was positive for the corresponding resistance ( $a a c-a p h D$ and $a a d D)$ genes. The tet $K$ was the gene determinant for tetracycline-resistant $S$. aureus in CC1, CC8, CC97, and CC152 (Table 2).

\section{Capsule typing, detection of virulence genes, and hemolytic activity}

WGS of selected $S$. aureus $(\mathrm{n}=37)$ representing each spa type established that capsule type 5 was associated with CC1, CC5, CC8, CC97, and CC152. Capsule type 8 was identified with $\mathrm{CC} 1, \mathrm{CC} 5, \mathrm{CC} 15, \mathrm{CC} 30, \mathrm{CC} 45$, CC121, CC133, and CC522 (Table 2). The sea-sep genes were detected in $\mathrm{CC} 1, \mathrm{CC} 5$, and $\mathrm{CC} 152$. Only one CC1MRSA was seh-positive. The distribution of the enterotoxin genes and clonal lineages revealed that $S$. aureus isolates in CC45, CC133 (sec-positive), and CC522 were tst-positive. Moreover, the bi-component leukocidin (lukF-P83/lukM) genes and sel were detected only in CC133 and CC522 (Table 2). Also, some CC5, CC8, and $\mathrm{CC} 15$ isolates were positive for $l u k D E$. The majority of isolates $(62 \%, 23 / 37)$ carried hla across the lineages, but this gene was not detected in CC522 by WGS (Table 2). 

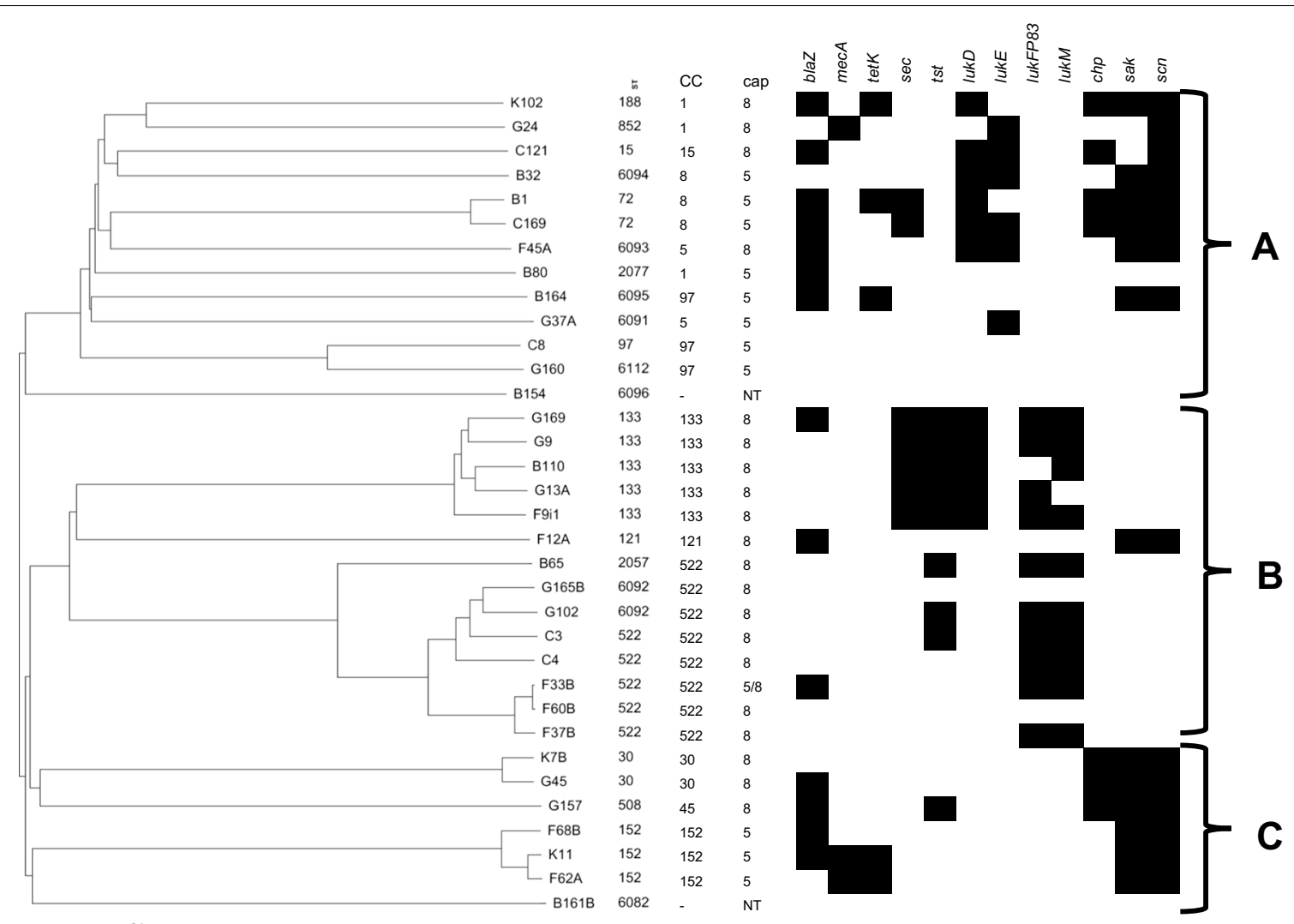

Fig. 2 A Neighbor-Joining (NJ) tree of selected S. aureus isolates based on up to 1861 genes of the S. aureus core genome (cg)MLST scheme and annotated with Clonal complex (CC), capsule type, and antibiotic and virulence gene carriage. ST, Sequence type; CC, clonal complex; cap, capsule; Antibiotic resistance genes and product (blaZ, $\beta$-lactamase; mecA, alternate penicillin-binding 2a; tetK, tetracycline efflux protein variant K). Enterotoxins and toxic shock syndrome genes (sec, enterotoxin C; tst, toxic shock syndrome toxin). Leukocidin and hemolysin genes (lukD, leukocidin D; lukE, leukocidin E; l lukF-P83, bovine Panton-Valentine leukocidin subunit F; lukM, leukocidin M). Immune evasion cluster genes (chp, chemotaxis-inhibiting protein; sak, staphylokinase; scn; staphylococcal complement inhibitor) $\square$ negative positive

However, representative CC522 isolates exhibited strong hemolysis on CBA (Fig. 3a). PCR confirmed that these isolates harbor hla and hlb (Additional file 5: Fig. S5). WGS also revealed that some S. aureus in CC5, CC97, CC133 (chp/sak/scn-negative), and CC152 (sak/scn-positive) carried the intact $h l b$ gene and confirmed by PCR. The complete $h l g$ operon comprising $h l g A, h l g B$ and $h l g C$ was identified in $S$. aureus assigned with $\mathrm{CC} 1, \mathrm{CC} 5, \mathrm{CC} 8$, CC15, CC30, CC45, CC121, and CC133. The exfoliative toxin $(e t A$ and $e t D)$ genes were detected in $\mathrm{CC15}(\mathrm{n}=1)$ and $\mathrm{CC} 1(\mathrm{n}=1)$, respectively and only CC152 isolates were $e \operatorname{din} B$-positive.

\section{MSCRAMMs genes and screening for mucoid phenotype and biofilm assay}

The most common protease gene was $\operatorname{sspB}$, and WGS identified the intercellular adhesion (icaA and icaC) genes in $>80 \%$ of isolates across the various CCs but absent in CC522 (Table 2; Additional file 6: Table S6). Also, PCR could not detect some portions of the icaA and icaC genes in representative CC522 isolates. However, t9268, t18946, and t19031 S. aureus in CC522 exhibited the mucoid phenotype on CBA. Besides, t9268 and t18946 isolates displayed rough colonies with wrinkled edges, while t19031 exhibited round, convex brown colonies on CRA (Fig. 3b). The MTP assay showed that all three isolates are biofilm producers. However, the biofilms attached to the bottom of the MTP appeared different from those produced by the PIA-positive $S$. aureus CF-7051800-I (5 bp del+) (Fig. 4a). The detachment assay also revealed that biofilms formed by the t9268 and t18946 isolates were susceptible to NMP, while the addition of proteinase K and DNase I had only minimal effects. This observation suggests that the biofilm mainly consists of an extracellular polysaccharide (EPS) and not PIA. The biofilm produced by t19031 S. aureus was equally dispersed by treatment with proteinase $\mathrm{K}, \mathrm{NMP}$, and DNase I (Fig. 4b). 

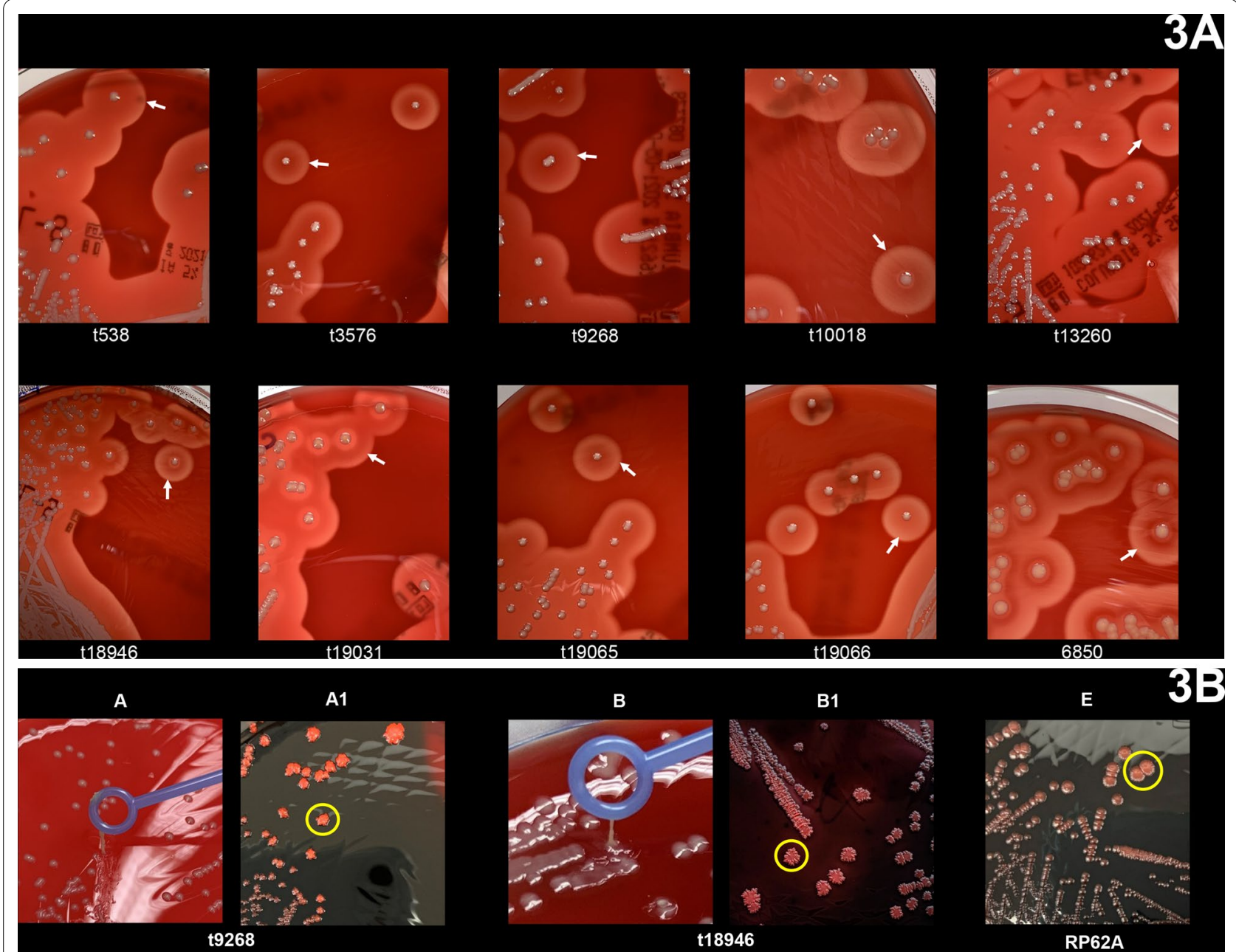

$\mathbf{E}$

$3 \mathbf{B}$

C

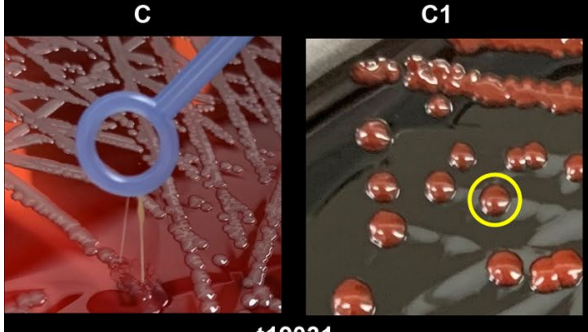

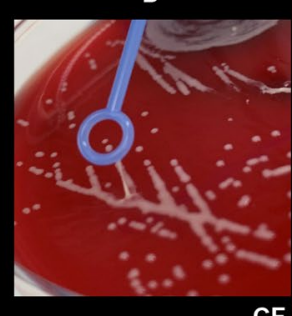

B1

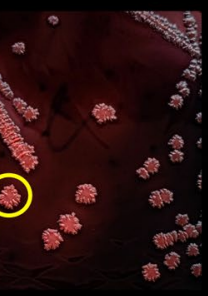

D1

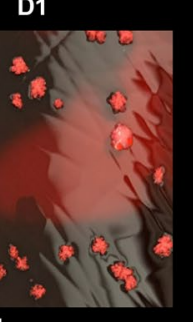

CF-70518005-I

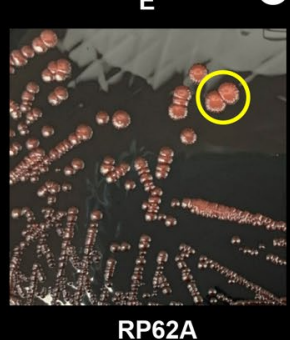

RP62A

Fig. 3 a Hemolytic activity of representative CC522 S. aureus isolates on Columbia Blood Agar (CBA). Positive control: highly invasive and cytotoxic strain S. aureus 6850. Colony sizes might differ due to different camera positions. The zone of hemolysis ( $\beta$-hemolysis) is indicated with an arrow. The spa types of representative CC522 S. aureus are presented. b Mucoid CC522 isolates on CBA and CRA. Key: A: Columbia Blood Agar (CBA); B: Congo Red Agar (CRA). A, B, C, D: mucoid phenotype; A1, B1, D1, E: pink/brown colonies with wrinkled, irregular edges; C1: brown colonies with smooth, convex, entire edges; F: pink colonies with smooth, convex, entire edges. Positive control: RP62A—S. epidermidis (biofilm-positive); 70518005-I: cystic fibrosis (CF) S. aureus isolate with a 5 bp deletion within the intergenic region of the ica operon [32] (biofilm/PIA-positive); Negative control S. carnosus TM300 (biofilm-negative). The spa types of mucoid CC522 S. aureus are indicated. Colony morphology is highlighted, and sizes might differ due to different camera positions

\section{Cytotoxicity assay}

We observed that WGS detected less virulence (enterotoxins and toxic shock syndrome, leukocidins and hemolysins, exfoliative toxins) genes in CC522 S. aureus (median: 3; range 1-7) compared with CC133 (median: 10; range 9-11, Table 2). Thus, we explored 


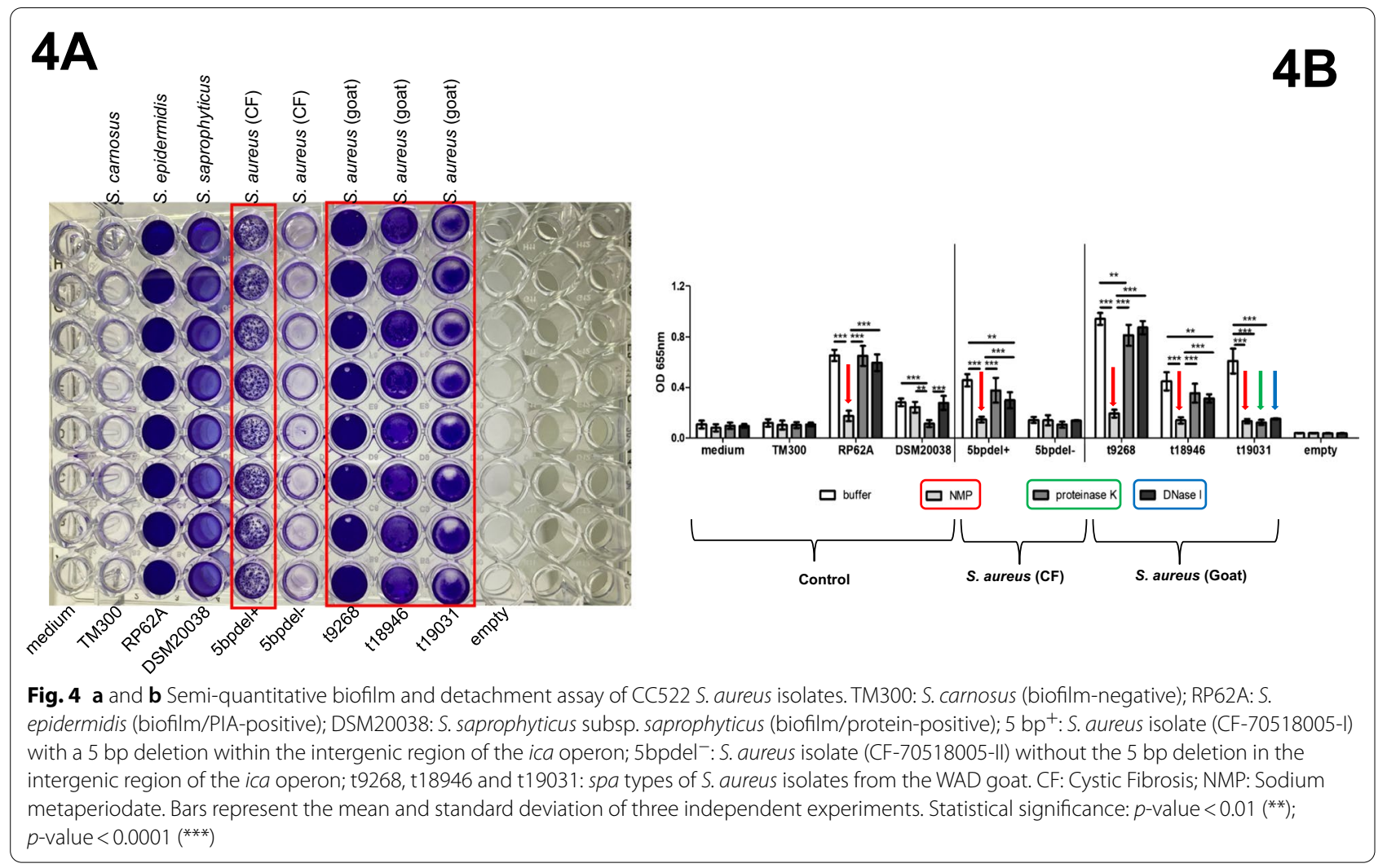

the pathogenic potential of the CC522 lineage by investigating the cytotoxicity of secreted products of representative $S$. aureus on A549 cells. The assay showed that $\mathrm{t} 538, \mathrm{t} 3576, \mathrm{t} 10018, \mathrm{t} 18946, \mathrm{t} 19031$ isolates were strongly cytotoxic compared with the control (sterile TSB) (Fig. 5).

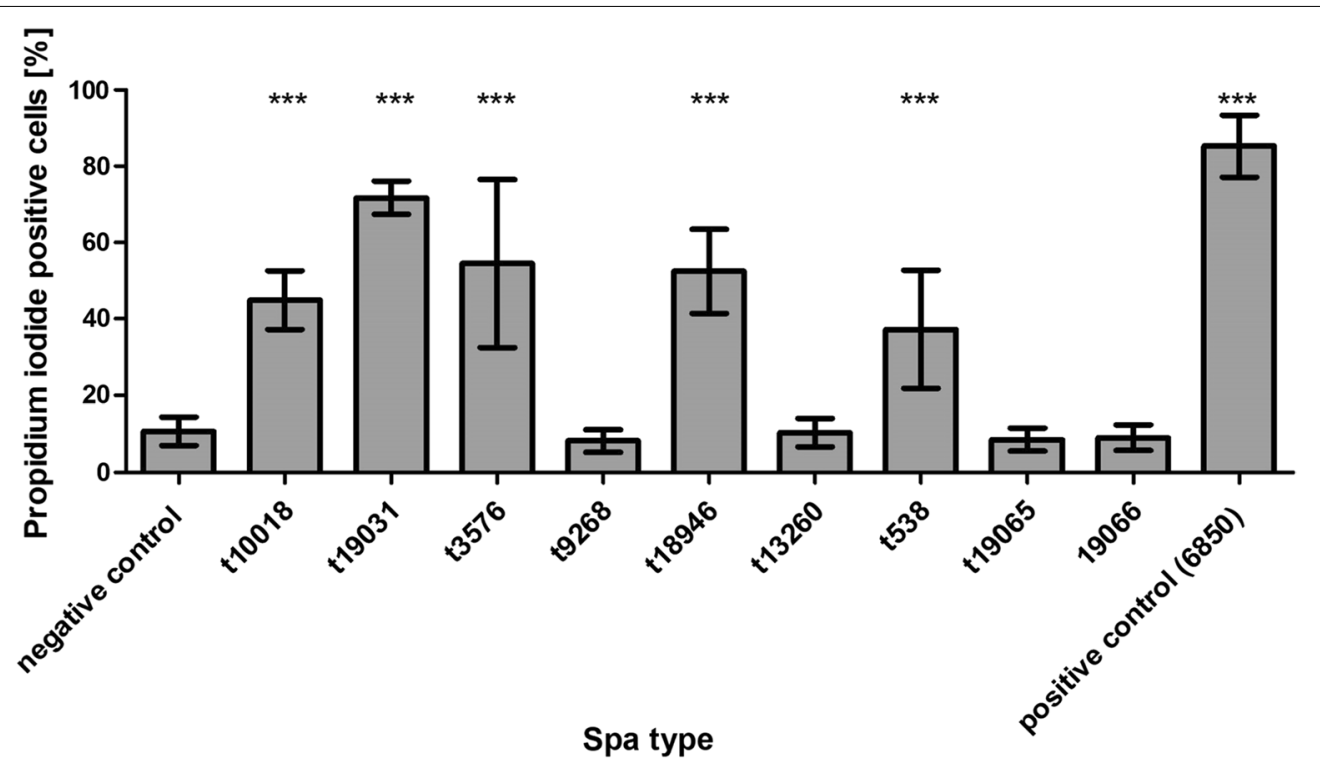

Fig. 5 Extracellular cytotoxicity on A549 cells of S. aureus isolates representing spa types associated with CC522. Bars represent the mean and standard deviation of five independent experiments. Statistical significance: $p$-value $<0.0001\left(^{* * *}\right)$. Positive control: highly invasive and cytotoxic strain S. aureus 6850. Negative control: TSB broth 


\section{Discussion}

This study revealed a low prevalence of antibiotic-resistant $S$. aureus in the WAD goat in Nigeria. Only 4\% (4/90) were identified as MRSA. Our observation is similar to previous goat studies in China [35], Iran [36], Nigeria [37], and Poland [38]. Penicillin and tetracycline are commonly used antibiotics in poultry and livestock farming in Nigeria [39, 40]. Our informal interaction with the goat sellers revealed that tetracycline and metronidazole are the common antibiotics administered to the ruminant animal. However, antibiotic use on the WAD goat is limited, which could be a plausible reason for the low percentage of antibiotic-resistant $S$. aureus observed in this study. Molecular typing and phylogenetic analysis also revealed that the $S$. aureus population of the WAD goat comprised primarily of CC133 and CC522 that are well adapted with ruminants. CC522 is one of the dominant $S$. aureus lineages among the goat population in China [35], Iran [36], Spain [41], and Tunisia [42]. It is also the main lineage in the anterior nares of healthy ewes in Tunisia [43]. The report of CC522 among the goat population in China and Iran suggests that this lineage may not be restricted to Africa and Europe, as postulated with sheep [44]. In this study, S. aureus assigned with t3576 and t10018 were the most common spa types and accounted for $64 \%(27 / 42)$ of the isolates in CC522. These genotypes have been identified from nasal samples of animals, including a farmworker (t10018) in Nigeria [37]. Besides, WGS showed that the t3576 and t10018 isolates were tst-positive (Table 2), which is similar to data from sheep [43] and dairy cows [45].

Although CC522 S. aureus was generally susceptible to all antibiotics and lacked many virulence genes based on WGS, the representative isolates demonstrated strong hemolytic activity and were confirmed as hla and $h l b$ positive. Moreover, t538, t3576, t10018, t18946, t19031 isolates showed strong cytotoxicity on A549 cells, unlike t9268, t13260, t19065, and t19066 S. aureus (Fig. 5). The reason for the variation is not clear. However, we postulate that strain specificity and level of expression of the hemolysins and/or other toxins [46] could be plausible reasons. Several methods have been employed for the detection and measurement of microbial biofilms [47]. In this study, the combination of touching single colonies with a sterile inoculating loop on CBA to assess the consistency and morphological characteristics on CRA was helpful in the presumptive identification of biofilmproducing $S$. aureus. We also demonstrated that CC522 $S$. aureus from the WAD goats could form biofilms. The semi-quantitative MTP and detachment assay provided evidence that the biofilm consists of an EPS and not PIA, as indicated by PCR and WGS. The nature of the EPSassociated biofilm is earmarked for further investigation.
Overall, the ability of CC522 S. aureus to form biofilms, detection of tst, hla, hlb, and cytotoxic effect on A549 cells, regardless of their susceptibility to antibiotics, illustrate their pathogenic capability.

CC133 was the second most common group, which agrees with previous studies that it is frequently associated with ruminants $[5,44,48-50]$. There is evidence that CC133 could have evolved due to a human to ruminant host jump followed by adaptive genome diversification [51]. In this study, the sec and tst genes located on the $S$. aureus pathogenicity island SaPIov1 were unique for the CC133 isolates, as previously noted $[5,50]$. CC 97 , the third most common group, is a leading cause of bovine mastitis globally [52]. WGS showed that the isolates generally lacked the leukocidin and enterotoxin genes. However, PCR revealed that most of the CC97 isolates were sak + , suggesting a human host association.

The prevalence of human-associated lineages (CC1, CC5, CC8, CC15, CC30, CC45, CC121, and CC152) was lower $(28 \%, 25 / 90)$ than animal-associated clones $(68 \%$, 65/90). S. aureus in CC1, CC30, CC121, and CC152 possessed the PVL genes, while the $l u k D E$ genes were identified in CC5, CC8, and CC15 (Table 2). PVL and LukDE are bi-component pore-forming leukocidins carried on the temperate phage $\Phi S \mathrm{~S} 2$ and $S$. aureus pathogenicity island $\mathrm{vSa} \beta$, respectively [53]. PVL-positive $S$. aureus is associated with subclinical mastitis in goats, while $l u k D E$ has a remarkable ability to target the lymphocytes of a broad host range [53]. Our observation of PVL-positive $S$. aureus from the WAD goat is similar to a study in China [35] and food-producing animals in Senegal [54]. PVL-positive $S$. aureus from colonized and clinical samples of humans has been widely reported in sub-Saharan Africa [55]. These findings indicate the possible impact of human-animal interaction on cross-species transmission.

MRSA has already been detected from the WAD goat in Nigeria [37, 56]. However, their molecular characteristics have not been well described. We identified MRSA with the following genotypes: t127-ST852-CC1SCCmecVII, t4690-ST152-CC152-SCCmecVc, and t8821-ST152-CC152-SCCmecVc. ST852, a single locus variant (slv) of ST1, is the third most common MSSA clone associated with human infections in five major African towns [57]. It is also noteworthy that PVL-positive CC152-MRSA was recovered from the WAD goat. Although the CC152-MRSA lacked most of the enterotoxin and toxic shock genes, the isolates were positive for the hemolysins ( $h l a, h l b, h \lg A, h l g B)$ and epidermal differentiation factor B (edinB). WGS also revealed that the CC152 isolates (scn/sak-positive) possessed an intact $h l b$ confirmed by PCR. This observation suggests new non-hlb-converting phages or alternative integration sites $[29,58]$. The PVL-positive CC152 lineage is 
a successful MSSA clone among humans and animals in Africa [55, 59], including Nigeria [6, 12, 60]. The emergence of PVL-positive ST852/CC1 and ST152/ CC152 MRSA indicates that it is important to understand the dynamics for introducing and acquiring the methicillin resistance ( $\operatorname{mec} A$ ) gene in these two successful African MSSA clones. Our work has limitations. First, we observed a poor agreement between WGS and conventional PCR in detecting some $S$. aureus antibiotic and virulence genes. Targets for WGS were considered as present if they were discovered in the genome with a range of $\geq 95 \%$ sequence identity and $\geq 99 \%$ query overlap to any of the sequences stored in the allele library [61]. Testing with appropriate and less restrictive threshold settings might provide increased concordance with PCR. Second, cultural and religious barriers could not allow us to investigate nasal and hand $S$. aureus carriage of close human contacts with the ruminant animal to address transmission and possible spread of antibiotic resistance genes. Social engagement and awareness on "One Health" with the evaluation of environmental samples are earmarked in subsequent investigations.

\section{Conclusion}

Our study provides the first detailed analysis of the population structure and genomic content of $S$. aureus from the WAD goat in Nigeria. The S. aureus clonal population of the WAD goat is diverse, including new spa types and STs. This observation indicates limited existing data and the need for more surveillance studies on animal $S$. aureus. We present evidence that the $S$. aureus clonal population of the WAD goat consists of both ruminantassociated lineages, and human-associated clones. We also highlight the pathogenic potential of the antibioticsusceptible and tst-positive CC522 S. aureus.

\footnotetext{
Abbreviations

ANOVA: Analysis of variance; AST: Antibiotic susceptibility testing; CBA: Columbia blood agar; CC: Clonal complex; cgMLST: Core genome multilocus sequence typing; chp: Chemotaxis-inhibiting protein; CRA: Congo red agar; DNase: Deoxyribonuclease; EPS: Extracellular polysaccharide; EUCAST: European committee on antimicrobial susceptibility testing; IEC: Immune evasion cluster; lukF-PV: Panton-valentine leukocidin subunit F; lukS-PV: Panton-valentine leukocidin subunit S; MALDI-TOF: Matrix assisted laser desorption ionization-time of flight; mecA: Methicillin resistance gene; MGEs: Mobile genetic elements; MRSA: Methicillin-resistant Staphylococcus aureus; MSCRAMM: Microbial surface components recognizing adhesive matrix molecules; MTP: Microtiter plate; NJ: Neighbor-joining; NMP: Sodium metaperiodate; NRPS: Nonribosomal peptide synthetase; PCR: Polymerase chain reaction; PIA: Polysaccharide intercellular adhesin; PI: Propidium iodide; PVL: Panton-Valentine leukocidin; sak: Staphylokinase; S. aureus: Staphylococcus aureus; SCCmec: Staphylococcal cassette chromosome mec; scn: Staphylococcal complement inhibitor; Spa: Staphylococcal protein A; ST: Sequence type; TSB: Tryptone soy broth; WAD: West African Dwarf; WGS: Whole-genome sequencing.
}

\section{Supplementary Information}

The online version contains supplementary material available at https://doi. org/10.1186/s13756-021-00987-8.

Additional file 1: Table S1. Phenotypic and molecular characteristics of Staphylococcus aureus isolates from nasal samples of the WAD goat in Nigeria.

Additional file 2: Table S2. Percentage and level of agreement between antibiotic susceptibility testing (AST) and WGS with representative $S$. aureus isolates ( $n=37$ ) from the WAD goat in Nigeria..

Additional file 3: Figure S3. Distribution of spa-CC of S. aureus isolates from the WAD goat in Nigeria. Legend: Multilocus sequence typing (MLST) of the isolates was determined from WGS assembled files processed through the S. aureus (cg) MLST scheme. The sequence types (STs) were subsequently related to clonal complexes (CCS) using the eBURST algorithm. *new spa types.

Additional file 4: Table S4. Percentage and level of agreement between $P C R$ and WGS in the detection of PVL and IEC genes from representative $S$. aureus isolates $(n=37)$ from the WAD goat in Nigeria.

Additional file 5: Figure S5. PCR detection of $h / a$ and $h / b$ in S. aureus isolates representing various CCs. Legend: Gene and gene product: hla: $201 \mathrm{bp} ;$ h/b 1+2: 534bp; h/b 2+3: $900 \mathrm{bp} ;$ h/b 3+4: 140bp.

Additional file 6: Table S6. Characterization and detection of selected antibiotic resistance and virulence genes (WGS) in S. aureus isolates from the WAD goat in Nigeria.

\section{Acknowledgements}

We appreciate the kind assistance and cooperation of the goat sellers in the sample locations in Osun State, Nigeria, and the Veterinary Services, Ministry of Agriculture, Osun State, Nigeria. We appreciate the valuable discussions with Barbara C. Kahl and the kind assistance of Beate Schule, Daniela Kuhn, and Akintunde Sallam.

\section{Authors' contributions}

Conceptualization, AOS and FS; Investigation, AOS, FFT and BS; Methodology, BS, NJF, SN, and AM; Validation, NJF, BS, SN, AM, and FS; Analysis, BS, SN, AM, and FS; Data curation, AM; Supervision, Project administration, Resources, Funding acquisition, FS. Writing-Original Draft, AOS. All authors reviewed and agreed to the final manuscript.

\section{Funding}

Open Access funding enabled and organized by Projekt DEAL. This study received support from the Deutsche Forschungsgemeinschaft (SCHA 1994/51, granted to AOS and FS) and the Alexander von Humboldt Foundation ("Georg Forster-Forschungsstipendium" granted to AOS). This study was also supported by a grant from the Innovative Medical Research (IMF; SC111911) of the Medical Faculty (Universitätsklinikum Münster) to BS. We acknowledge support from the Open Access Publication Fund of the University of Muenster.

\section{Availability of data and materials}

The data from the study is provided in Additional files.

\section{Declarations}

\section{Ethics approval and consent to participate}

Written informed consent to participate in the study was obtained from the goat sellers, including ethical approval from the Institute of Public Health, Obafemi Awolowo University (IPH/OAU/12/1054; IPH/OAU/12/1495) and the Veterinary Services, Ministry of Agriculture, Osun State, Nigeria (VD/AN/0201).

Consent for publication

Not applicable.

Competing interests

The authors declare no competing interests in the conduct of this research. 


\section{Author details}

${ }^{1}$ Department of Microbiology, Obafemi Awolowo University, Ile-Ife, Nigeria. ${ }^{2}$ Institute of Medical Microbiology, University Hospital Münster, Domagkstraße 10, 48149 Münster, Germany. ${ }^{3}$ Institute for Hygiene, University Hospital Münster, Robert-Koch-Straße 41, 48149 Münster, Germany.

\section{Received: 30 April 2021 Accepted: 26 July 2021} Published online: 19 August 2021

\section{References}

1. Heaton CJ, Gerbig GR, Sensius LD, Patel V, Smith TC. Staphylococcus aureus epidemiology in wildlife: a systematic review. Antibiotics. 2020.

2. Murray S, Pascoe B, Méric G, Mageiros L, Yahara K, Hitchings MD, et al. Recombination-mediated host adaptation by avian Staphylococcus aureus. Genome Biol Evol. 2017.

3. Haag AF, Fitzgerald JR, Penadés JR. Staphylococcus aureus in animals. Microbiol Spectr. 2019.

4. Richardson EJ, Bacigalupe R, Harrison EM, Weinert LA, Lycett S, Vrieling M, et al. Gene exchange drives the ecological success of a multi-host bacterial pathogen. Nat Ecol Evol. 2018.

5. Merz A, Stephan R, Johler S. Staphylococcus aureus isolates from goat and sheep milk seem to be closely related and differ from isolates detected from bovine milk. Front Microbiol. 2016.

6. Abubakar U, Sulaiman SAS. Prevalence, trend and antimicrobial susceptibility of methicillin resistant Staphylococcus aureus in Nigeria: a systematic review. J Infect Public Health. 2018;11:763-70. https://doi.org/10.1016/j. jiph.2018.05.013.

7. Abdulgader SM, Shittu AO, Nicol MP, Kaba M. Molecular epidemiology of Methicillin-resistant Staphylococcus aureus in Africa: a systematic review. Front. Microbiol. 2015

8. Obasuyi O, McClure J, Oronsaye FE, Akerele JO, Conly J, Zhang K. Molecular characterization and pathogenicity of Staphylococcus aureus isolated from Benin-City, Nigeria. Microorganisms. 2020

9. Ghebremedhin B, Olugbosi MO, Raji AM, Layer F, Bakare RA, König B, et al. Emergence of a community-associated methicillin-resistant Staphylococcus aureus strain with a unique resistance profile in Southwest Nigeria. J Clin Microbiol. 2009:47:2975-80.

10. Shittu AO, Okon K, Adesida S, Oyedara O, Witte W, Strommenger B, et al. Antibiotic resistance and molecular epidemiology of Staphylococcus aureus in Nigeria. BMC Microbiol. 2011;11:92

11. Momoh AH, Kwaga JKP, Bello M, Sackey AKB, Larsen AR. Antibiotic resistance and molecular characteristics of Staphylococcus aureus isolated from backyard-raised pigs and pig workers. Trop Anim Health Prod United States. 2018:50:1565-71.

12. Okorie-Kanu OJ, Anyanwu MU, Ezenduka EV., Mgbeahuruike AC, Thapaliya D, Gerbig G, et al. Molecular epidemiology, genetic diversity and antimicrobial resistance of Staphylococcus aureus isolated from chicken and pig carcasses, and carcass handlers. PLOS ONE. 2020

13. Otalu OJ, Kwaga JKP, Okolocha EC, Islam MZ, Moodley A. High genetic similarity of MRSA ST88 isolated from pigs and humans in Kogi state. Nigeria Front Microbiol. 2018:9:3098.

14. Ogundipe FO, Ojo OE, Feßler AT, Hanke D, Awoyomi OJ, Ojo DA, et al. Antimicrobial resistance and virulence of methicillin-resistant Staphylococcus aureus from human, chicken and environmental samples within live bird markets in three Nigerian cities. Antibiotics. 2020

15. Aziz MA. Present status of the world goat populations and their productivity. Lohmann Inf. 2010.

16. Chiejina SN, Behnke JM. The unique resistance and resilience of the Nigerian West African Dwarf goat to gastrointestinal nematode infections. Parasit Vectors. 2011:4:12. https://doi.org/10.1186/1756-3305-4-12.

17. FAO. Tranforming livestock sector: Nigeria. Africa Sustain Livest 2050; 2019

18. Brakstad OG, Aasbakk K, Maeland JA. Detection of Staphylococcus aureus by polymerase chain reaction amplification of the NUC gene. J Clin Microbiol. 1992

19. Zhang DF, Xu X, Song Q, Bai Y, Zhang Y, Song M, et al. Identification of Staphylococcus argenteus in Eastern China based on a nonribosomal peptide synthetase (NRPS) gene. Future Microbiol. 2016.
20. Murakami K, Minamide W, Wada K, Nakamura E, Teraoka H, Watanabe S. Identification of methicillin-resistant strains of staphylococci by polymerase chain reaction. J Clin Microbiol. 1991.

21. Harmsen D, Claus H, Witte W, Rothgänger J, Claus H, Turnwald D, et al. Typing of methicillin-resistant Staphylococcus aureus in a university hospital setting by using novel software for spa repeat determination and database management. J Clin Microbiol. 2003.

22. Lina G, Piemont Y, Godail-Gamot F, Bes M, Peter M-O, Gauduchon V, et al. Involvement of Panton-Valentine Leukocidin-Producing Staphylococcus aureus in primary skin infections and pneumonia. Clin Infect Dis. 1999.

23. Van Wamel WJB, Rooijakkers SHM, Ruyken M, Van Kessel KPM, Van Strijp JAG. The innate immune modulators staphylococcal complement inhibitor and chemotaxis inhibitory protein of Staphylococcus aureus are located on $\beta$-hemolysin-converting bacteriophages. J Bacteriol. 2006.

24. Mellmann A, Bletz S, Böking T, Kipp F, Becker K, Schultes A, et al. Real-time genome sequencing of resistant bacteria provides precision infection control in an institutional setting. J Clin Microbiol. 2016.

25. Phaku $P$, Lebughe $M$, Strauß L, Peters G, Herrmann M, Mumba D, et al. Unveiling the molecular basis of antimicrobial resistance in Staphylococcus aureus from the democratic republic of the Congo using whole genome sequencing. Clin Microbiol Infect. 2016.

26. Kaya H, Hasman H, Larsen J, Stegger M, Johannesen TB, Allesøe RL, et al. SCCmecFinder, a web-based tool for typing of staphylococcal cassette chromosome MEC in Staphylococcus aureus using whole-genome sequence data. mSphere. 2018;3.

27. Lennartz FE, Schwartbeck B, Dübbers A, Große-Onnebrink J, Kessler C, Küster $\mathrm{P}$, et al. The prevalence of Staphylococcus aureus with mucoid phenotype in the airways of patients with cystic fibrosis-A prospective study. Int J Med Microbiol. 2019.

28. Treffon J, Fotiadis SA, Van Alen S, Becker K, Kahl BC. The virulence potential of livestock-associated methicillin-resistant Staphylococcus aureus cultured from the airways of cystic fibrosis patients. Toxins (Basel). 2020.

29. Van Alen S, Ballhausen B, Kaspar U, Köck R, Becker K. Prevalence and genomic structure of bacteriophage phi3 in human-derived livestockassociated methicillin-resistant Staphylococcus aureus isolates from 2000 to 2015. J Clin Microbiol. 2018.

30. Kouidhi B, Zmantar T, Hentati H, Bakhrouf A. Cell surface hydrophobicity, biofilm formation, adhesives properties and molecular detection of adhesins genes in Staphylococcus aureus associated to dental caries. Microb Pathog. 2010; 49:14-22. doi: https://doi.org/10.1016/j.micpath. 2010.03.007

31. Freeman DJ, Falkiner FR, Keane CT. New method for detecting slime production by coagulase negative staphylococci. J Clin Pathol. 1989;42:8724. https://pubmed.ncbi.nlm.nih.gov/2475530.

32. Schwartbeck B, Birtel J, Treffon J, Langhanki L, Mellmann A, Kale D, et al. Dynamic in vivo mutations within the ICA operon during persistence of Staphylococcus aureus in the airways of cystic fibrosis patients. PLoS Pathog. 2016.

33. Grossmann A, Froböse NJ, Mellmann A, Alabi AS, Schaumburg F, Niemann S. An in vitro study on Staphylococcus schweitzeri virulence. Sci Rep. 2021;11:1157. https://doi.org/10.1038/s41598-021-80961-x.

34. Landis JR, Koch GG. The measurement of observer agreement for categorical data. Biometrics. 1977.

35. Zhou Z, Zhang M, Li H, Yang H, Li X, Song X, et al. Prevalence and molecular characterization of Staphylococcus aureus isolated from goats in Chongqing, China. BMC Vet Res. 2017.

36. Dastmalchi Saei H, Panahi M. Genotyping and antimicrobial resistance of Staphylococcus aureus isolates from dairy ruminants: differences in the distribution of clonal types between cattle and small ruminants. Arch Microbiol. 2020

37. Odetokun IA, Ballhausen B, Adetunji VO, Ghali-Mohammed I, Adelowo MT, Adetunji SA, et al. Staphylococcus aureus in two municipal abattoirs in Nigeria: risk perception, spread and public health implications. Vet Microbiol. 2018

38. Moroz A, Szaluś-Jordanow O, Czopowicz M, Brodzik K, Petroniec V, Augustynowicz-Kopeć E, et al. Nasal carriage of various staphylococcal species in small ruminant lentivirus-infected asymptomatic goats. Pol J Vet Sci. 2020.

39. Alhaji NB, Aliyu MB, Ghali-Mohammed I, Odetokun IA. Survey on antimicrobial usage in local dairy cows in North-central Nigeria: drivers for misuse and public health threats. PLoS One. 2019;14:0224949. 
40. Oloso NO, Adeyemo IA, van Heerden H, Fasanmi OG, Fasina FO. Antimicrobial drug administration and antimicrobial resistance of salmonella isolates originating from the broiler production value chain in Nigeria. Antibiot (Basel, Switzerland). 2019;8.

41. Concepción Porrero M, Hasman H, Vela Al, Fernández-Garayzábal JF, Domínguez L, Aarestrup FM. Clonal diversity of Staphylococcus aureus originating from the small ruminants goats and sheep. Vet Microbiol. 2012.

42. Gharsa H, Slama K Ben, Gómez-Sanz E, Lozano C, Zarazaga M, Messadi L, et al. Molecular characterization of Staphylococcus aureus from nasal samples of healthy farm animals and pets in Tunisia. Vector-Borne Zoonotic Dis. 2015.

43. Ben Said M, Abbassi MS, Gómez P, Ruiz-Ripa L, Sghaier S, El Fekih O, et al. Genetic characterization of Staphylococcus aureus isolated from nasal samples of healthy ewes in Tunisia. High prevalence of CC130 and CC522 lineages. Comput Immunol Microbiol Infect Dis. 2017.

44. Smith EM, Needs PF, Manley G, Green LE. Global distribution and diversity of ovine-associated Staphylococcus aureus. Infect Genet Evol. 2014.

45. Mekonnen SA, Lam TJGM, Hoekstra J, Rutten VPMG, Tessema TS, Broens EM, et al. Characterization of Staphylococcus aureus isolated from milk samples of dairy cows in small holder farms of North-Western Ethiopia. BMC Vet Res. 2018;14:246. https://doi.org/10.1186/s12917-018-1558-1.

46. Strobel M, Pförtner H, Tuchscherr L, Völker U, Schmidt F, Kramko N, et al. Post-invasion events after infection with Staphylococcus aureus are strongly dependent on both the host cell type and the infecting S. aureus strain. Clin Microbiol Infect Off Publ Eur Soc Clin Microbiol Infect Dis. England; 2016;22:799-809.

47. Azeredo J, Azevedo NF, Briandet R, Cerca N, Coenye T, Costa AR, et al. Critical review on biofilm methods. Crit Rev Microbiol. 2017;43:313-51. https://doi.org/10.1080/1040841X.2016.1208146.

48. Conceição T, De Lencastre H, Aires-De-Sousa M. Healthy bovines as reservoirs of major pathogenic lineages of Staphylococcus aureus in Portugal. Microb Drug Resist. 2017.

49. Hoekstra J, Rutten VPMG, van den Hout M, Spaninks MP, Benedictus L, Koop G. Differences between Staphylococcus aureus lineages isolated from ovine and caprine mastitis but not between isolates from clinical or subclinical mastitis. J Dairy Sci. 2019.

50. Romanò A, Gazzola A, Bianchini V, Cortimiglia C, Maisano AM, Cremonesi $P$, et al. Staphylococcus aureus from goats are genetically heterogeneous and distinct to bovine ones. Front Vet Sci. 2020

51. Guinane CM, Zakour NLB, Tormo-Mas MA, Weinert LA, Lowder B V., Cartwright RA, et al. Evolutionary genomics of Staphylococcus aureus reveals insights into the origin and molecular basis of ruminant host adaptation. Genome Biol Evol. 2010.

52. Naushad S, Nobrega DB, Naqvi SA, Barkema HW, De Buck J. Genomic analysis of bovine Staphylococcus aureus isolates from milk to elucidate diversity and determine the distributions of antimicrobial and virulence genes and their association with mastitis. mSystems. 2020.

53. Spaan AN, Van Strijp JAG, Torres VJ. Leukocidins: Staphylococcal bicomponent pore-forming toxins find their receptors. Nat Rev Microbiol. 2017.

54. Mama OM, Dieng M, Hanne B, Ruiz-Ripa L, Diop CGM, Torres C. Genetic characterisation of staphylococci of food-producing animals in Senegal. PVL detection among MSSA. BMC Vet Res. 2019;15:1-6.

55. Schaumburg F, Alabi AS, Peters G, Becker K. New epidemiology of Staphylococcus aureus infection in Africa. Clin. Microbiol. Infect. 2014.

56. Omoshaba EO, Ojo OE, Oyekunle MA, Sonibare AO, Adebayo AO. Methicillin-resistant Staphylococcus aureus (MRSA) isolated from raw milk and nasal swabs of small ruminants in Abeokuta, Nigeria. Trop Anim Health Prod. 2020.

57. Breurec S, Zriouil SB, Fall C, Boisier P, Brisse S, Djibo S, et al. Epidemiology of methicillin-resistant Staphylococcus aureus lineages in five major African towns: emergence and spread of atypical clones. Clin Microbiol Infect. 2011.

58. Argudín MÁ, Mendoza MC, Rodicio MR. Food poisoning and Staphylococcus aureus enterotoxins. Toxins (Basel). 2010.

59. Lozano C, Gharsa H, Ben Slama K, Zarazaga M, Torres C. Staphylococcus aureus in animals and food: methicillin resistance, prevalence and population structure. A review in the African Continent. Microorganisms. 2016.

60. O'Malley SM, Emele FE, Nwaokorie FO, Idika N, Umeizudike AK, EmekaNwabunnia I, et al. Molecular typing of antibiotic-resistant Staphylococcus aureus in Nigeria. J Infect Public Health. 2015.

61. Strauß L, Ruffing U, Abdulla S, Alabi A, Akulenko R, Garrine M, et al. Detecting Staphylococcus aureus virulence and resistance genes: a comparison of whole-genome sequencing and DNA microarray technology. J Clin Microbiol. 2016;54:1008-16.

62. Ojurongbe O, Akindele AA, Adeleke MA, Oyedeji MO, Adedokun SA, Ojo $J F$, et al. Co-endemicity of Loiasis and Onchocerciasis in rain forest communities in Southwestern Nigeria. PLoS Negl Trop Dis. 2015.

\section{Publisher's Note}

Springer Nature remains neutral with regard to jurisdictional claims in published maps and institutional affiliations.
Ready to submit your research? Choose BMC and benefit from:

- fast, convenient online submission

- thorough peer review by experienced researchers in your field

- rapid publication on acceptance

- support for research data, including large and complex data types

- gold Open Access which fosters wider collaboration and increased citations

- maximum visibility for your research: over 100M website views per year

At BMC, research is always in progress.

Learn more biomedcentral.com/submissions 